\title{
Examination on the lightning breakdown strength of biodegradable oil under quasi- uniform field
}

\begin{abstract}
Among the alternative fluids considered for application in transformers are Palm Oil (PO) and Coconut Oil (CO). Among the important studies that need to be carried out before it can be applied in-service is the lightning impulse performance. This paper presents the experimental work on the lightning impulse breakdown voltage of different $\mathrm{PO}, \mathrm{CO}$ and Mineral Oil (MO). The PO used in this is the Refined Bleached Deodorized Palm Oil (RBDPO) type. The test was carried out under quasi-uniform field using sphere-sphere electrode configuration with different testing methods (rising-voltage and up-and-down). It was found that the lightning impulse performance for some of RBDPO and CO were comparable to MO.
\end{abstract}

Keyword: Transformer; Lightning breakdown voltage; Quasi-uniform field; Palm oil; Coconut oil; Mineral oil 